\title{
COVID-19: Success Depends on Medical Concepts, Not Political Views
}

\author{
Igor Klepikov* \\ $M D$, professor, retired. USA. \\ *Corresponding Author: Igor Klepikov, MD, professor, retired. USA.
}

\section{OPEN LETTER}

The appearance of the current COVID-19 pandemic has not only significantly changed the usual rhythm and conditions of our life, but also came as a direct surprise to many, causing a sense of anxiety and insecurity. As the new situation developed and its consequences accumulated, long-standing problems that had previously gone unnoticed or unimportant for many were increasingly identified. And if a year ago the discussion of these issues was not perceived properly in the medical community, today the situation itself dictates the need for such an analysis. Moreover, the pandemic has come as a complete surprise to the vast majority of specialists, depriving them of their usual treatment regimens, and the current offers and efforts of medical care are symptomatic and do not affect the overall results.

At this time, when the coronavirus pandemic is an indisputable fact, it is difficult to refute the claims that this catastrophe has been steadily approaching us for many years. The main problem of coronavirus infection is the development of a viral form of pneumonia with all possible consequences. Viruses have long appeared in the description of pathogens of acute pneumonia (AP), but in previous years their independent role in the development of this disease was more declarative, and viral infections were considered as harbingers of bacterial inflammation.

Over the past couple of decades, the number of cases of viral pneumonia has increased, and repeated epidemics of viral infections have clearly demonstrated the consequences of their outbreaks. Suffice it to recall the SARS (20022004) and MERS (2012-2013) epidemics, which are now referred to by the additional terms $\mathrm{CoV}$ and $\mathrm{CoV}-1$ in contrast to the current $\mathrm{CoV}-2$ pandemic, which indicates an etiological connection between these events (1). what conclusions did modern medicine draw from the first two relatively local catastrophes? What practical steps have been taken in the future in the event of a repeat of such natural disasters? The answers to these questions lie in the nature of medical care for coronavirus pneumonia, when it became absolutely clear that there is no comprehensive specific treatment for such patients, since previously the basis of treatment was antibiotics, which are not suitable in this situation.

Treatment of patients with AP only on the basis of antibiotics remained the leading strategy all these years, and under this psychological burden, bacterial forms of the disease that are not contagious and not prone to epidemics were classified as infectious. This concept remained a priority until the beginning of Cov-2, when many leading specialists continued to consider antibiotics as a "cornerstone" in the treatment of patients with AP (2,3). Has anyone questioned the therapeutic effectiveness of antibiotics for AP, which act only on the microbial factor and do not have a direct effect on the inflammatory process? Or someone wondered why one antibiotic can act as the main (!) treatment not only for AP, but also for a number of diverse and heterogeneous inflammatory diseases?

The belief in the indispensability of antibiotics in the treatment of inflammatory diseases, absorbed over many years and memorized by heart, made us forget about the importance and role of the fundamental foundations of medical science. The unique features of the development and course of AP, in contrast to acute inflammations of other localization, remain without attention, proper assessment and professional understanding. Treatment of aggressive forms of AP on the same principles as, for example, diarrhea or peritonitis, can not give other results than the existing sad statistics. Hope for intensive care in specialized institutions fades in the process of its provision, as the death rate from AP in emergency departments reaches $40-50 \%$ (4). 
As the current reality shows, the narrow approach and treatment regimens for AP continue to determine strategy and tactics during the current pandemic. Declaring the priority of suppressing the pathogen and the need to create antiviral drugs in the future, modern practical medicine continues to automatically apply antibiotics in more than $70-80 \%$ of patients with coronavirus, without having direct indications for this and knowing in advance about the futility of such treatment (5-7). While remaining true to previous ideas about the leading role of the AP pathogen and its virulence, experts do not have an answer or a scientific explanation for why in a monoetiological pandemic, most infected people remain asymptomatic, and among patients there is a huge range of clinic options (8-10).

In the end, the set of tools and methods for helping patients with coronavirus looks very primitive and cannot guarantee targeted assistance in the case of "COVID-19 pneumonia" (11). If today approaches such as careful monitoring of patients in order to select the appropriate time for intubation (12), the supply of oxygen in the prone positioning to increase oxygenation and reduce the risk of subsequent intubation (4,13-15), as well as recommendations for increasing the production of ventilators (16) are seriously discussed as key measures to help patients with coronavirus pneumonia, what success can be expected from such a "strategy" in treatment? In fact, in this case, we are no longer talking about chasing the virus, but about eliminating the influence of the focus of inflammation on the vital functions of the body.

The question of what to do, which is now facing everyone involved in the health care system, has only one answer. If the problem-solving strategy fails, it means that the ideology does not correspond to the essence and nature of the observed events and requires immediate and thorough analysis based on facts, objective evidence and fundamental scientific materials, rather than on assumptions and guesses.

If we see that a patient with a coronavirus infection has shortness of breath, then its cause is no longer the virus, but the consequences of its impact in the form of inflammatory transformation of the lung tissue. Suppressing the pathogen during this period will not bring instant results. It is necessary to influence the focus of inflammation and the mechanisms of its influence on the body's functions. Oxygen supply is a purely symptomatic, not pathogenetic care measure that does not affect the dynamics of the inflammatory process. If the patient has reached the stage of artificial ventilation, many of them have already crossed the line of returning to the starting position.

Pathogenetic approaches to the treatment of patients with aggressive forms of AP today can radically change the results. This statement is not another Declaration of intent, as it is based on the extensive work already done with successful clinical testing. At that time, an unshakeable belief in antibiotics did not allow many to pay attention to the immediacy and simplicity of such treatment. However, a combination of circumstances forced even then to look for a way out of a difficult situation. The circumstances and features of this work, which was completed more than 30 years ago, as well as the reasons why its further continuation was interrupted, are described in detail in the recently published monograph: Igor Klepikov "Acute pneumonia. New doctrine and first treatment results " - ISBN (978-620-2-67917-6) $>$ \{https://www. cheapesttextbooks. com/ IM/ ?keyval=ISBN+\%28978-620-2-67917-6\%29 \}.

In this context, we are talking about a single nosological form, AP, which, regardless of etiological factors and individual variants, has a single mechanism of development and functional disorders. Medical science has accumulated a sufficient number of important and proven materials that remain unclaimed in emergency pulmonology, but which allow us to change the concept of views on the nature of AP and formulate pathogenetic care. Such a critical analysis, first of all, should be expected from specialists who hold senior positions and determine the ideology of the direction. Such actions are logical and correspond to the title of a doctor, specialist, scientist. Unfortunately and to no small surprise, in the section of assistance to patients with AP, medicine continues to operate according to the previous schemes, and to justify its short-sightedness and inertia, it tries to find an explanation in a completely unexpected unprofessional direction.

The author of these lines knows firsthand what the politicization of science is. I was born and lived most of my life in a country where science, especially its biomedical branches, was often used for political purposes, distorting facts and even denying scientific arguments. The consequences of such steps in the future required time and a lot of effort to eliminate them. 
This option of political correction of scientific views is inherent in regimes with an authoritarian form of government, is determined from above by the leadership of the state and acts as an order. But today, during the pandemic, there is a reverse form of political application of science. Medicine was not up to par not only in providing medical care, but also in the ability to calmly and authoritatively explain the observed phenomena and clearly demonstrate its psychotherapeutic role in society. The lack of a reliable medical strategy to overcome this situation and the psychological impact of daily updated statistics on morbidity and mortality increase the anxiety in society and bring certain segments of it out of balance.

The fact that daily media coverage of the pandemic plays a negative role in public sentiment can be illustrated by comparative statistics. During the COVID-19 pandemic, about 40 million people were infected worldwide and 1.1 million deaths were recorded by mid-October 2020 (https://covid19info.live/). Of course, these figures are impressive, since each unit hides the fate of a particular person, especially when every day, often automatically, you can get information about how these indicators are growing.

But, recently, there was a specific statistical data, according to the AP, which greatly exceeded these figures. For example, about 450 million cases of AP were registered annually worldwide (as opposed to the total number of people infected with COVID-19) and about 4 million deaths $(17,18)$. These figures, which can shock anyone, were not known even to some specialists and did not have any effect on the usual order and rhythm of life, since they were not particularly advertised even in the specialized literature.

Today, medical problems that do not have clear explanations and solutions are increasingly used in many countries for political purposes, when competitors in the power struggle begin to blame each other for medical problems instead of complaining about the short-sightedness and narrowness of the stereotypical views of doctors. When such accusations are made by people who are far from medicine, this can still be explained and understood, but when this political discussion is joined by the voices of specialists responsible for the interpretation and dissemination of professional medical information, who, judging by the tone of the presentation, are not particularly concerned with problems of medical competence, this becomes a landmark phenomenon (19).

The content and meaning of this publication is particularly surprising in the light of the materials presented above. It turns out that the whole problem of high morbidity and mortality from coronavirus in the United States is not medical, but political in nature and, according to the authors, lies only in the incompetence of Federal leaders. By the way, it is appropriate to note that in a number of media reports about the pandemic, it was noted that the most unfavorable situations with the spread of the virus and infection of the population were observed in States whose leaders are opponents of the current Federal government. When chaos and disorder arise under the slogans of democracy, it is no longer democracy, but anarchy and lawlessness. Thus, the authors are indeed correct in the following statement: "But the one we can control is how we behave. And in the United States we have consistently behaved poorly"(19). And here it is necessary to add that we act in accordance with our ideas and thoughts.

Political preferences are not related to professional training, but the discussion of such topics on the pages of scientific publications only complicates the perception of specific information and leads away from the discussion of really important issues. It would be much more interesting, more important, and more necessary to get an editorial opinion on why infection with an equivalent virus provides an infinite range of clinical options, leaving most of the population just carriers of it. At the same time, patients who have successfully survived the coronavirus disease cannot be counted among the successes of modern medicine with its current therapeutic approaches. Here it is worth Recalling the old expression that came to us from the middle Ages, that nature itself treats most of its patients, without requiring gratitude and recognition for this.

But the mortality rate in the current pandemic cannot be viewed from the point of view of the obvious hopelessness of such patients. It wasn't the Federal government that treated these patients, was it? Let's say frankly that the majority of patients who died from coronavirus are on the conscience of modern medicine, which could not provide the necessary assistance to the sick body in its adaptation to the aggressiveness of the disease. This is a topic that requires a comprehensive professional 
discussion and appropriate solutions. Let's not look for a cat in a dark room, which is not there, and do their direct professional duties.

\section{REFERENCES}

[1] https://en.wikipedia.org/wiki/Severe_acute_res piratory_syndrome

[2] Paula Peyrani, Lionel Mandell, Antoni Torres \& Glenn S Tillotson (2019) The burden of community-acquired bacterial pneumonia in the era of antibiotic resistance, Expert Review of Respiratory Medicine, 13:2, 139-152, DOI: 10.1080/17476348.2019.1562339

[3] J. P. Metlay, G. W. Waterer, A. C. Long at al.; on behalf of the American Thoracic Society and Infectious Diseases Society of America. "Diagnosis and Treatment of Adults with Community-acquired Pneumonia. An Official Clinical Practice Guideline of the American Thoracic Society and Infectious Diseases Society of America". American Journal of Respiratory and Critical Care Medicine, Volume 200, Issue 7, 1 October 2019, Pages e45-e67, https://www.atsjournals. org/doi/ full/ 10.1164/rccm.201908-1581ST

[4] Renato Seligman and Beatriz Graeff Santos Seligman. "Pandemic in the 21st Century. The Challenge of COVID-19". EC Pulmonology and Respiratory Medicine 9.8 (2020): 30-31.

[5] Rawson TM, Moore LSP, Zhu N, et al. (2020). Bacterial and fungal co-infection in individuals with coronavirus: A rapid review to support COVID-19 antimicrobial prescribing [published online ahead of print, 2020 May 2]. Clin Infect Dis. 2020;ciaa530. doi:10.1093 /cid/ciaa530

[6] Beović, M. Doušak, J. Ferreira-Coimbra et al. (2020). Antibiotic use in patients with COVID19: a 'snapshot' Infectious Diseases International Research Initiative (ID-IRI) survey. Journal of Antimicrobial Chemotherapy, dkaa326, https://doi.org/ 10. 1093/jac/dkaa326

[7] Kim D , Quinn J , Pinsky B et al. (2020). Rates of co-infection between SARS-CoV-2 and other respiratory pathogens. JAMA 2020; 323: 2085-6.

[8] A. Sakurai, T. Sasaki, S. Kato et al. (2020). Natural History of Asymptomatic SARS-CoV-
2 Infection. NEJM, June 12, 2020, DOI: 10.1056/NEJMc2013020

[9] Keeley AJ, Evans CM, de Silva TI (2020). Asymptomatic SARS-CoV-2 infection: the tip or the iceberg? Thorax 2020;75:621-622.

[10] Ing AJ, Cocks C, Green JP (2020). COVID-19: in the footsteps of Ernest Shackleton. Thorax, 2020; 75:693-694.

[11] Lipman M, Chambers RC, Singer M, et al. (2020). SARS-CoV-2 pandemic: clinical picture of COVID-19 and implications for research. Thorax 2020; 75:614-616.

[12] D. A. Berlin, R. M. Gulick, F. J. Martinez (2020). Severe Covid-19. NEJM, May 15, 2020, DOI: $10.1056 / \mathrm{NEJMcp} 2009575$

[13] Koeckerling D, Barker J, Mudalige NL, et al. (2020). Awake prone positioning in COVID19. Thorax Published Online First: 16 June 2020. doi: 10.1136/thoraxjnl-2020-215133

[14] Thompson AE et al. (2020) Prone positioning in awake, nonintubated patients with COVID19 hypoxemic respiratory failure. JAMA Intern Med 2020 Jun 17; [e-pub]. (https://doi.org/ 10.1001/jamainternmed.2020.3030)

[15] Winearls S, Swingwood EL, Hardaker CL, et al. (2020). Early conscious prone positioning in patients with COVID-19 receiving continuous positive airway pressure: a retrospective analysis. BMJ, Open Respiratory Research, 2020;7:e000711. doi: 10.1136/bmjresp-2020-00 0711

[16] M. L. Ranney, V. Griffeth, A. K. Jha (2020). Critical Supply Shortages - The Need for Ventilators and Personal Protective Equipment during the Covid-19 Pandemic. NEJM, 2020; 382:e41 DOI: 10.1056/ NEJMp2006141

[17] Rudan I, Boschi-Pinto C, Biloglav Z, Mulholland K, Campbell H. Epidemiology and etiology of childhood pneumonia. Bull World Health Organ. 2008;86:408-416. [PMC free article] [PubMed] [Google Scholar]

[18] WHO Revised global burden of disease 2002 estimates. 2004. http://www.who. int/healthinfo /global_burden_disease/ estimates_regional _2002_revised/en/ (accessed Nov 5, 2010).

[19] Editorial from The New England Journal of Medicine (2020). Dying in a Leadership Vacuum. N Engl J Med 2020; 383:1479-1480. DOI: 10.1056/NEJM, e2029812

Citation: Igor Klepikov, "COVID-19: Success Depends on Medical Concepts, Not Political Views", International Journal of Research Studies in Medical and Health Sciences. 2020; 5(10): 11-14.

Copyright: (0) 2020 Igor Klepikov, This is an open-access article distributed under the terms of the Creative Commons Attribution License, which permits unrestricted use, distribution, and reproduction in any medium, provided the original author and source are credited. 